\title{
Comparison of sterols and fatty acids in two species of Ganoderma
}

Guang-ping LV $v^{1,2}$, Jing Zhao ${ }^{1,2^{*}}$, Jin-ao Duan ${ }^{3}$, Yu-ping Tang ${ }^{3}$ and Shao-ping Li $\mathrm{i}^{12^{*}}$

\begin{abstract}
Background: Two species of Ganoderma, G. sinense and G. lucidum, are used as Lingzhi in China. Howerver, the content of triterpenoids and polysaccharides, main actives compounds, are significant different, though the extracts of both G. lucidum and G. sinense have antitumoral proliferation effect. It is suspected that other compounds contribute to their antitumoral activity. Sterols and fatty acids have obvious bioactivity. Therefore, determination and comparison of sterols and fatty acids is helpful to elucidate the active components of Lingzhi.

Results: Ergosterol, a specific component of fungal cell membrane, was rich in G. lucidum and G. sinense. But its content in G. Iucidum (median content $705.0 \mu \mathrm{g} \cdot \mathrm{g}^{-1}$, range 189.1-1453.3 $\mu \mathrm{g} \cdot \mathrm{g}^{-1}, \mathrm{n}=19$ ) was much higher than that in G. sinense (median content $80.1 \mu \mathrm{g} \cdot \mathrm{g}^{-1}$, range 16.0-409.8 $\mu \mathrm{g} \cdot \mathrm{g}^{-1}, \mathrm{n}=13$ ). Hierarchical clustering analysis based on the content of ergosterol showed that 32 tested samples of Ganoderma were grouped into two main clusters, $G$. lucidum and G. sinense. Hierarchical clustering analysis based on the contents of ten fatty acids showed that two species of Ganoderma had no significant difference though two groups were also obtained. The similarity of two species of Ganoderma in fatty acids may be related to their antitumoral proliferation effect.

Conclusions: The content of ergosterol is much higher in G. lucidum than in G. sinense. Palmitic acid, linoleic acid, oleic acid, stearic acid are main fatty acids in Ganoderma and their content had no significant difference between G. lucidum and $G$. sinense, which may contribute to their antitumoral proliferation effect.
\end{abstract}

\section{Background}

Ganoderma (Lingzhi in Chinese) is a genus of wellknown medicinal mushrooms with multiple benefits to human health. So far, more than 120 species of Ganoderma have been reported in the world, 98 species of which could be found in China [1]. However, only two species of Ganoderma (Figure 1), G. lucidum (Leyss.ex Fr.) Karst. and G. sinense Zhao, Xu et Zhang, are documented as Lingzhi in Chinese Pharmacopoeia (2010) [2]. Modern studies have revealed that Lingzhi contain a variety of bioactive ingredients, including triterpenoids, polysaccharides, sterols, fatty acids, nucleosides and alkaloids [3], and possess multiple pharmacological activities, such as antitumor [1,4], immunomodulation $[5,6]$, anti-inflammatory [7], antiviral [8], anti-aging [9] and anti-diabetic [10] effects. It is usually considered that triterpenoids and polysaccharides are the main

\footnotetext{
* Correspondence: zhaojing.cpu@163.com; lishaoping@hotmail.com

${ }^{1}$ State Key Laboratory of Quality Research in Chinese Medicine, University of Macau, Macao SAR 999078, China

Full list of author information is available at the end of the article
}

active components in Lingzhi [3]. However, our previous study has revealed that the contents of triterpenes are significantly different between G. lucidum and G. sinense [11]. Actually, little or no triterpene was detected in $G$. sinense $[1,11,12]$. It is very interesting that ethanol extracts of both G. lucidum and G. sinense, at the same cytotoxicity concentration, have similar antitumoral proliferation effect through both apoptosis pathway and cell cycle arrest effect [1], which indicates that some other compounds may contribute to their activity besides triterpenoids and polysaccharides.

To date, several sterols and fatty acids, which have significant bio-functions in fungi $[13,14]$, were separated or identified from Ganoderma [7,8,15-17]. Ergosterol and its analogues contained in Ganoderma had multiple pharmacological effects such as anti-HIV-1 [7], anti-complement [8], anti-aging [9] activities, and protecting cerebral cortical neurons from hypoxia/reoxygenation injury [18]. On the other hand, free fatty acids (FFAs) are not only essential nutritional ingredients but also significant to many cellular functions through receptors of FFAs [19]. Especially, 


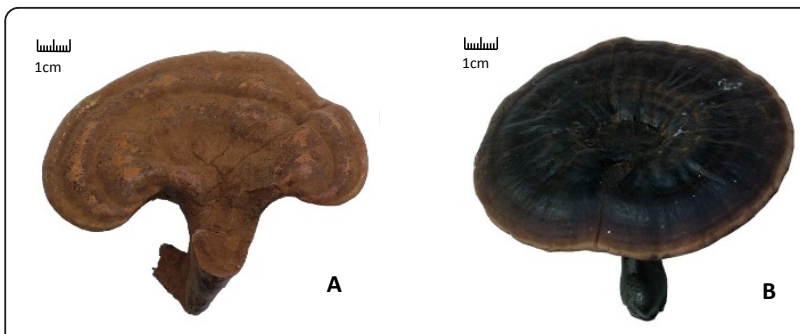

Figure 1 Raw materials of (A) Ganoderma lucidum and (B) Ganoderma sinense.

long chain fatty acids in the spores of G. lucidum could triggers tumor cell death through induction of apoptosis [20]. Therefore, analysis of sterols and fatty acids in two species of Ganoderma is not only important for evaluation of their quality but also beneficial to the elucidation of their pharmacological activities.

Up to date, TLC [21-23], HPLC [11,24-28], GC [16,29-31], MEKC [32] have been developed for analysis of triterpenoids [11,21-24,26,27], polysaccharides [25,28-31] and nucleosides [32] in Ganoderma. However, few researches focus on the analysis of sterols or fatty acids in Ganoderma $[15,16,33]$. In present study, ergosterol and ten free fatty acids, including lauric acid (C12:0), myristic acid (C14:0), pentadecanoic acid (C15:0), palmitic acid (C16:0, PA), palmitoleic acid (C16:1), stearic acid (C18:0, SA), oleic acid (C18:1, OA), linoleic acid (C18:2, LoA), docosanoic acid (C22:0) and lignoceric acid (C24:0), in two species of Ganoderma were determined by using pressurized liquid extraction (PLE) and GC-MS analysis after one-step TMS derivatization. The contents of the free sterol and fatty acids in G. lucidum and G. sinense were also compared.

\section{Experimental}

Materials and chemicals

Lauric acid (C12:0, dodecanoic acid), myristic acid (C14:0, tetradecanoic acid), pentadecanoic acid (C15:0), palmitic acid (C16:0, hexadecanoic acid), palmitoleic acid (C16:1, (Z)-hexadec-9-enoic acid), stearic acid (C18:0, octadecanoic acid), oleic acid (C18:1, (Z)-octadec-9-enoic acid), linoleic acid (C18:2, (9Z,12Z)-octadeca-9,12-dienoic acid), docosanoic acid (C22:0), lignoceric acid (C24:0, tetracosanoic acid) and ergosterol were purchased from Sigma (St. Louis, MO, USA). Petroleum ether $\left(60-90^{\circ} \mathrm{C}\right)$ and $n$-hexane were purchased from Merck (Darmstadt, Germany). Derivatization reagent BSTFA (N, O-bis (trimethylsilyl) trifluoroacetamide) containing 1\% TMCS (trimethylchlorosilane) was purchased from Supelco (St. Louis, MO, USA). Reagents not mentioned here were from standard sources. The materials of Ganoderma were obtained from different locations in China (Table 1). Voucher specimens of
Table 1 Summary for the tested samples of Ganoderma

\begin{tabular}{|c|c|c|c|}
\hline No. & Code & Samples & Sources \\
\hline 1 & GL-1 & G. lucidum & Dabieshan, Anhui, China \\
\hline 2 & GL-2 & G. lucidum & Dabieshan, Anhui, China \\
\hline 3 & GL-3 & G. lucidum & Jinzhai, Anhui, China \\
\hline 4 & $\mathrm{GL}-4$ & G. lucidum & Jiaxiang, Shandong, China \\
\hline 5 & GL-5 & G. lucidum & Guanxian, Shandong, China \\
\hline 6 & GL-6 & G. lucidum & Jingzhou, Hunan, China \\
\hline 7 & GL-7 & G. lucidum & Jingning, Zhejiang, China \\
\hline 8 & GL-8 & G. lucidum & Liangshan, Shandong, China \\
\hline 9 & GL-9 & G. lucidum & Emei, Sichuan, China \\
\hline 10 & GL-10 & G. lucidum & Emei, Sichuan, China \\
\hline 11 & GL-11 & G. lucidum & Jiaxiang, Shandong, China \\
\hline 12 & GL-12 & G. lucidum & Beijing, China \\
\hline 13 & GL-13 & G. lucidum & Dabieshan, Anhui, China \\
\hline 14 & GL-14 & G. lucidum & Jinzhai, Anhui, China \\
\hline 15 & GL-15 & G. lucidum & Anshun, Guizhou, China \\
\hline 16 & GL-16 & G. lucidum & Guanxian, Shandong, China \\
\hline 17 & GL-17 & G. lucidum & Dabieshan, Anhui, China \\
\hline 18 & GL-18 & G. lucidum & Emei, Sichuan, China \\
\hline 19 & GL-19 & G. lucidum & Anshun, Guizhou, China \\
\hline 20 & GS-1 & G. sinense & Dabieshan, Anhui, China \\
\hline 21 & GS-2 & G. sinense & Jinzhai, Anhui, China \\
\hline 22 & GS-3 & G. sinense & Dabieshan, Anhui, China \\
\hline 23 & GS-4 & G. sinense & Dabieshan, Anhui, China \\
\hline 24 & GS-5 & G. sinense & Pingguo, Guangxi, China \\
\hline 25 & GS-6 & G. sinense & Liangshan, Shandong, China \\
\hline 26 & GS-7 & G. sinense & Pingguo, Guangxi, China \\
\hline 27 & GS-8 & G. sinense & Liangshan, Shandong, China \\
\hline 28 & GS-9 & G. sinense & Beijing, China \\
\hline 29 & GS-10 & G. sinense & Jingzhou, Hunan, China \\
\hline 30 & GS-11 & G. sinense & Jinzhai, Anhui, China \\
\hline 31 & GS-12 & G. sinense & Jinzhai, Anhui, China \\
\hline 32 & GS-13 & G. sinense & Macao, China \\
\hline
\end{tabular}

these samples were deposited at the Institute of Chinese Medical Sciences, University of Macau, Macao, China.

\section{Sample preparation}

Pressurized liquid extractions were performed on a Dionex ASE 200 (Dionex Corp., Sunnyvale, CA, USA) system. In brief, $0.2 \mathrm{~g}$ powder of Ganoderma were mixed with diatomaceous earth in a proportion (1:1) and placed into an $11 \mathrm{ml}$ stainless steel extraction cells, respectively. The extraction with petroleum ether was performed under optimized conditions: temperature, $160^{\circ} \mathrm{C}$; static extraction time, $10 \mathrm{~min}$; pressure, $1500 \mathrm{psi}$; flush volume, $40 \%$; static cycle 1 and one for the number of extraction. The extract (approximate $15 \mathrm{~mL}$ ) was dried under $\mathrm{N}_{2}$ (Organomation Associates, Inc., Berlin, MA, USA), then $100 \mu \mathrm{L}$ derivatization agent (BSTFA) and $400 \mu \mathrm{L} n$-hexane were added to the residue and reacted at $70^{\circ} \mathrm{C}$ for $30 \mathrm{~min}$. The derivative mixture was 
dried under $\mathrm{N}_{2}$ to remove the excess BSTFA, and subsequently re-dissolved in $1 \mathrm{~mL} n$-hexane. The solution was filtered through a $0.45 \mu \mathrm{m}$ Econofilter (Agilent Technologies, Palo Alto, CA, USA) before GC-MS analysis.

\section{GC-MS analysis}

GC-MS was performed with an Agilent 6890 gas chromatography instrument coupled to an Agilent 5973 mass spectrometer and an Agilent ChemStation software (Agilent Technologies, Palo Alto, CA). A capillary column $(30 \mathrm{~m} \times 0.25 \mathrm{~mm}$ i.d.) coated with $0.25 \mu \mathrm{m}$ film $5 \%$ phenyl methyl siloxane was used for separation. High purity helium was used as carrier gas with flowrate at $1 \mathrm{ml} \cdot \mathrm{min}^{-1}$. The column temperature was set at $100^{\circ} \mathrm{C}$ and held for $5 \mathrm{~min}$ for injection, then programmed at $20^{\circ} \mathrm{C} \mathrm{min}^{-1}$ to $200^{\circ} \mathrm{C}$ and held for $10 \mathrm{~min}$, then at $10^{\circ} \mathrm{C} \mathrm{min}^{-1}$ to $230^{\circ} \mathrm{C}$, and finally, at $5^{\circ} \mathrm{C} \mathrm{min}^{-1}$ to $320^{\circ} \mathrm{C}$, and held for $5 \mathrm{~min}$. Split injection $(2 \mu \mathrm{L})$ with a split ratio of 1:10 (or 1:100 if the content of analytes beyond the upper limit of linearity ranges) was used, and injection temperature was set at $260^{\circ} \mathrm{C}$.

The spectrometers were operated in electron-impact (EI) mode, the scan range was 40-550 amu, the ionization energy was $70 \mathrm{eV}$ and the scan rate was 0.34 s per scan. The quadrupole, ionization source temperature were $150^{\circ} \mathrm{C}$ and $280^{\circ} \mathrm{C}$, respectively.

\section{Calibration curves}

Stock solutions containing 11 reference compounds were prepared and diluted into appropriate concentrations with n-hexane (Table 2) for the construction of calibration curves using SIM mode of GC-MS, and the fragment ions $m / z 257,285,299,313,311,341,339$, 337, 397, 425 and 363 were used for lauric acid (C12:0), myristic acid (C14:0), pentadecanoic acid (C15:0), palmitic acid (C16:0, PA), palmitoleic acid (C16:1), stearic acid (C18:0, SA), oleic acid (C18:1, OA), linoleic acid (C18:2, LoA), docosanoic acid (C22:0), lignoceric acid (C24:0) and ergosterol, respectively. At least six concentrations of the solution were analyzed in duplicates, and then the calibration curves were constructed by plotting the peak area versus the amount (ng) of each analyte.

\section{LOD and LOQ}

Stock solution containing 11 reference compounds was diluted to a series of appropriate concentrations with nhexane, and an aliquot of the diluted solutions was injected into GC-MS for analysis. The limits of detection (LOD) and quantification (LOQ) under the present chromatographic conditions were determined at the ratio of signal to noise $(\mathrm{S} / \mathrm{N})$ equal to 3 and 10 , respectively.

\section{Precision, repeatability and accuracy}

Intra-day, inter-day variations were chosen to determine the precision of the developed GC-MS assay. A certain concentration (about at the middle of linear range) solution of 11 reference compounds was tested. For intraday variability, the samples were analyzed for six times within one day, while for inter-day variability, the samples were examined in duplicate for consecutive three days. Variations were expressed by the relative standard deviations (RSD).

To test the repeatability of derivatization, PLE extract of sample GL-1 was divided into three and respectively derivatized under the optimum conditions then analyzed by GC-MS as mentioned above. Variations were expressed by RSD.

The recovery was used to evaluate the accuracy of the method. Accurate amounts of individual standards were added into a certain amount $(0.1 \mathrm{~g})$ of GL-1. The

Table 2 SIM, regression data, LOD, LOQ and recovery of 11 investigated compounds analyzed by GC-MS

\begin{tabular}{|c|c|c|c|c|c|c|c|}
\hline \multirow[t]{2}{*}{ Analytes } & \multirow[t]{2}{*}{ SIM } & \multicolumn{2}{|c|}{ Linear regression data } & \multirow[t]{2}{*}{$\mathrm{R}^{2}$} & \multirow{2}{*}{$\begin{array}{l}\text { LOD } \\
\text { (ng) }\end{array}$} & \multirow{2}{*}{$\begin{array}{c}\text { LOQ } \\
\text { (ng) }\end{array}$} & \multirow{2}{*}{$\begin{array}{l}\text { Recovery } \\
(\%, n=3\end{array}$} \\
\hline & & \multicolumn{2}{|c|}{ Regressive Equation Linear range (ng) } & & & & \\
\hline Lauric acid & 257 & $y=55788 x-7172$ & $0.2-4.7$ & 0.9991 & 0.070 & 0.132 & 99.5 \\
\hline Myristic acid & 285 & $y=92491 x-9626$ & $0.2-4.7$ & 0.9994 & 0.039 & 0.073 & 99.9 \\
\hline Pentadecanoic acid & 299 & $y=100984 x-19569$ & $0.3-8.6$ & 0.9998 & 0.065 & 0.123 & 98.5 \\
\hline Palmitoieic acid & 311 & $y=107565 x-28765$ & $0.4-11.8$ & 0.9994 & 0.084 & 0.231 & 99.1 \\
\hline Palmitic acid & 313 & $y=13939 x-713$ & $0.5-15.1$ & 0.9990 & 0.064 & 0.118 & 101.4 \\
\hline Linoleic acid & 337 & $y=16543 x-9768$ & $1.3-6.3$ & 0.9982 & 0.220 & 0.413 & 101.3 \\
\hline Oleic acid & 339 & $y=36027 x-9874$ & $0.4-7.0$ & 0.9992 & 0.119 & 0.155 & 101.1 \\
\hline Stearic acid & 341 & $y=68023 x-67$ & $0.3-37.7$ & 0.9995 & 0.141 & 0.268 & 96.9 \\
\hline Docosanoic acid & 397 & $y=103013 x-88418$ & $1.5-4.9$ & 0.9990 & 0.485 & 0.971 & 100.2 \\
\hline Lignoceric acid & 425 & $y=103037 x-35337$ & $0.6-9.3$ & 0.9984 & 0.223 & 0.527 & 97.3 \\
\hline Ergosterol & 363 & $y=40732 x-6971$ & $0.5-3.8$ & 0.9989 & 0.251 & 0.471 & 101.9 \\
\hline
\end{tabular}

${ }^{a}$ Recovery $(\%)=$ (amount found-original amount)/amount spiked. 


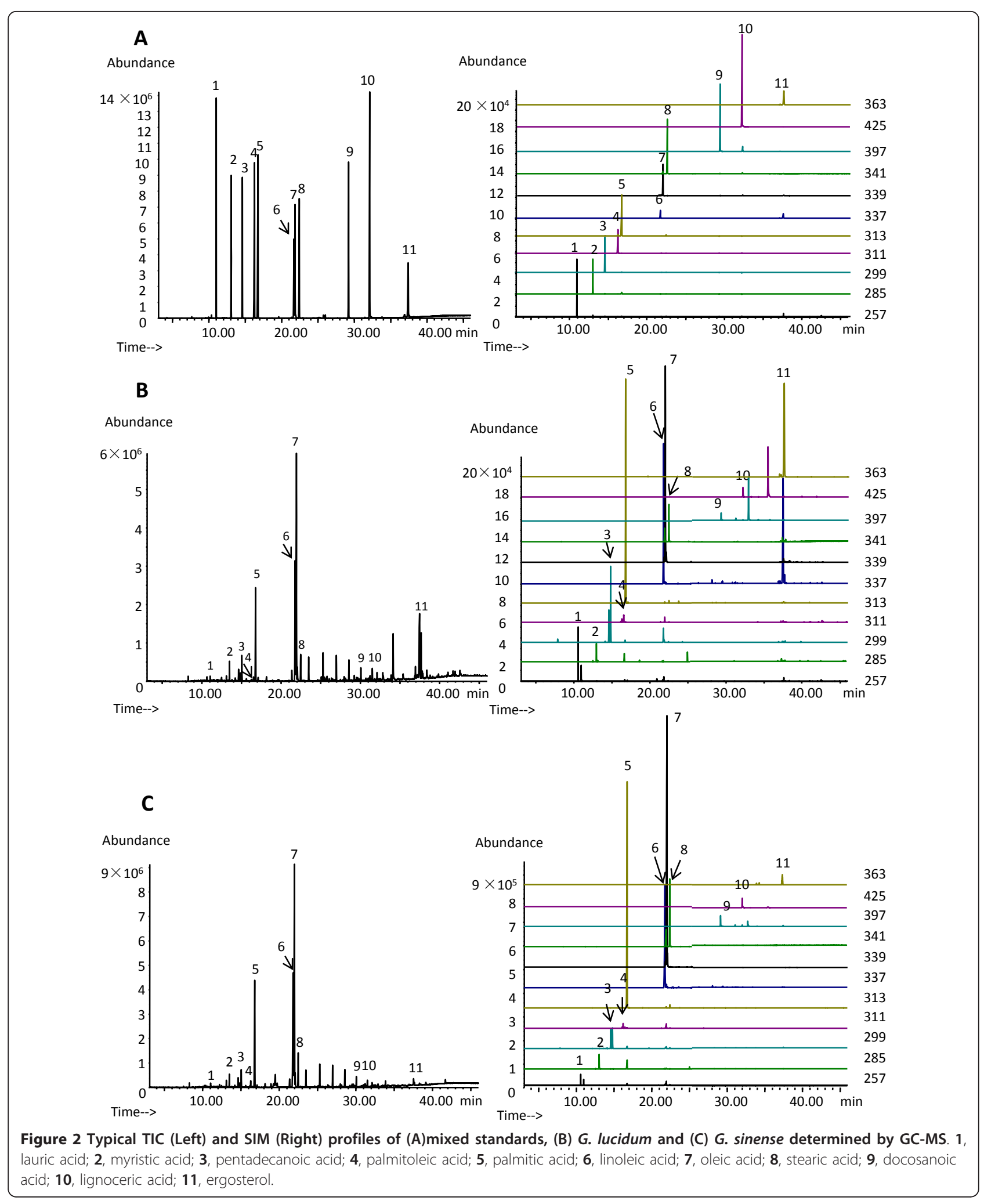


Table 3 The contents $\left(\mu \mathrm{g} \cdot \mathrm{g}^{-1}\right)$ of ten investigated fatty acids and ergosterol in Ganoderma

\begin{tabular}{|c|c|c|c|c|c|c|c|c|c|c|c|c|}
\hline Sample Code & LA & MA & PtA & PoA & PA & LoA & $\mathrm{OA}$ & SA & DA & LiA & FAs & ErS \\
\hline GL-1 & $13.4^{\mathrm{a}}$ & 14.7 & 20.7 & 14.5 & 99.0 & 543.7 & 1116.9 & 77.4 & 27.9 & 50.3 & 1978.5 & 189.1 \\
\hline GL-2 & 17.0 & 19.3 & 51.7 & 41.1 & 331.2 & 1718.1 & 2953.6 & 177.9 & 26.7 & 37.6 & 5374.2 & 240.9 \\
\hline GL-3 & 20.2 & 16.9 & 27.1 & 22.4 & 149.3 & 988.8 & 1678.1 & 112.4 & $+^{\mathrm{b}}$ & 40.3 & 3055.5 & 578.5 \\
\hline GL-4 & 12.1 & 12.3 & 26.6 & 12.9 & 141.7 & 872.2 & 894.3 & 71.6 & + & 21.8 & 2065.5 & 846.7 \\
\hline GL-5 & 14.3 & 14.4 & 38.9 & 16.6 & 261.0 & 1323.0 & 1625.0 & 119.3 & 24.9 & 29.7 & 3467.1 & 681.1 \\
\hline GL-6 & 17.5 & 16.1 & 37.3 & 16.1 & 242.0 & 1742.4 & 1651.0 & 114.9 & 24.6 & 28.1 & 3889.9 & 703.5 \\
\hline GL-7 & 13.6 & 13.4 & 31.6 & 22.1 & 181.6 & 1028.2 & 1378.2 & 108.3 & + & 19.9 & 2796.9 & 553.8 \\
\hline GL-8 & 14.5 & 16.8 & 30.6 & + & 170.6 & 971.2 & 1324.9 & 118.2 & 28.4 & 36.6 & 2711.8 & 719.0 \\
\hline GL-9 & 18.8 & 15.2 & 29.1 & 14.9 & 146.3 & 753.7 & 971.7 & 85.9 & + & 19.2 & 2054.8 & 1278.5 \\
\hline GL-10 & 18.0 & 15.2 & 19.2 & 14.4 & 181.7 & 783.2 & 1533.6 & 166.2 & 46.4 & 51.0 & 2828.9 & 691.1 \\
\hline GL-11 & 13.8 & 17.2 & 42.7 & 16.5 & 272.7 & 1819.0 & 1881.9 & 141.7 & 24.5 & 36.8 & 4266.8 & 664.6 \\
\hline GL-12 & 16.2 & 16.4 & 22.6 & 16.1 & 119.9 & 819.2 & 1226.5 & 90.3 & 24.0 & 31.3 & 2382.6 & 740.2 \\
\hline GL-13 & 20.9 & 20.7 & 36.4 & 7.5 & 255.4 & 992.3 & 2143.0 & 150.1 & 44.6 & 62.7 & 3733.6 & 812.2 \\
\hline GL-14 & 16.4 & 13.5 & 16.9 & + & 86.6 & 338.1 & 333.9 & 91.6 & + & 19.2 & 916.1 & 881.4 \\
\hline GL-15 & 13.6 & 13.0 & 15.2 & + & 73.2 & 327.2 & 239.1 & 46.2 & + & 22.9 & 750.2 & 705.0 \\
\hline GL-16 & 28.6 & 28.2 & 61.9 & 25.9 & 213.0 & 2578.0 & 2817.6 & 61.9 & + & 30.3 & 5845.4 & 1029.2 \\
\hline GL-17 & 20.1 & 20.8 & 49.4 & 19.2 & 328.7 & 2567.1 & 2645.6 & 111.9 & 29.1 & 48.7 & 5840.6 & 615.8 \\
\hline GL-18 & 18.9 & 15.3 & 29.8 & + & 160.1 & 913.4 & 793.7 & 71.0 & + & 37.4 & 2039.6 & 1453.3 \\
\hline GL-19 & 19.0 & 13.5 & 25.2 & 7.5 & 134.6 & 916.5 & 353.2 & 62.0 & + & 18.4 & 1549.8 & 1256.8 \\
\hline GS-1 & 16.9 & 18.9 & 19.1 & 8.5 & 249.8 & 1524.1 & 2314.0 & 202.9 & 24.0 & 52.1 & 4430.5 & 91.6 \\
\hline GS-2 & 22.0 & 35.2 & 59.6 & 34.2 & 840.2 & 3555.3 & 4847.6 & 299.2 & + & 42.1 & 9735.3 & 17.3 \\
\hline GS-3 & 18.7 & 20.1 & 21.3 & 13.7 & 176.3 & 1047.7 & 1668.2 & 123.9 & + & 34.9 & 3124.7 & 80.1 \\
\hline GS-4 & 21.8 & 19.6 & 24.1 & 14.1 & 215.2 & 1328.7 & 1889.7 & 132.9 & + & 32.7 & 3678.7 & 104.6 \\
\hline GS-5 & 18.3 & 19.1 & 30.2 & 16.2 & 304.7 & 1464.6 & 1625.1 & 152.7 & + & 29.6 & 3660.5 & 344.2 \\
\hline GS-6 & 19.0 & 29.8 & 47.6 & 19.2 & 656.4 & 3559.5 & 4283.3 & 306.2 & + & 55.4 & 8976.3 & 43.5 \\
\hline GS-7 & 19.3 & 21.6 & 65.0 & 7.4 & 187.7 & 1974.6 & 295.3 & 58.0 & + & 13.9 & 2642.6 & 331.3 \\
\hline GS-8 & 19.8 & 39.6 & 65.3 & 25.7 & 950.1 & 3920.5 & 5611.4 & 391.4 & + & 53.1 & 11076.8 & 18.0 \\
\hline GS-9 & 25.7 & 36.1 & 46.3 & 18.9 & 479.8 & 2656.5 & 3447.8 & 222.9 & + & 38.4 & 6972.3 & 24.9 \\
\hline GS-10 & 15.3 & 15.3 & 21.2 & + & 119.8 & 839.2 & 465.2 & 67.6 & + & 18.5 & 1562.1 & 369.3 \\
\hline GS-11 & 22.9 & 33.1 & 76.9 & 28.2 & 765.8 & 2955.2 & 3719.4 & 198.9 & + & 40.7 & 7841.1 & 20.5 \\
\hline GS-12 & 22.0 & 37.3 & 55.7 & 32.2 & 775.2 & 3339.8 & 4706.9 & 283.7 & + & 45.0 & 9297.9 & 16.0 \\
\hline GS-13 & 16.0 & 19.9 & 42.4 & 8.2 & 360.9 & 2145.2 & 1723.2 & 96.5 & + & 26.1 & 4438.4 & 409.8 \\
\hline
\end{tabular}

LA, lauric acid; MA, myristic acid; PtA, pentadecanoic acid; PoA, palmitoleic acid; PA, palmitic acid; LoA, linoleic acid; OA, oleic acid; SA, stearic acid; DA, docosanoic acid; LiA, lignoceric acid; ErS, ergosterol; FAs: total content of ten fatty acids

a The data are presented as average of duplicates.

${ }^{b}$ Under the limit of quantification.

mixture was extracted and analyzed using the developed method. Three replicates were performed for the test.

\section{Data analysis}

Hierarchical clustering analysis was performed by SPSS 18.0 for windows (SPSS Inc., Chicago, IL, USA), which comprise a number of "procedures" graphical, statistical, reporting, processing and tabulating procedures that enable simple and rapid data evaluation. Hierarchical cluster analysis was performed based on ergosterol and ten fatty acids characteristics from GC-MS profiles of 32 tested samples, respectively. Ward's method, a very efficient method for the analysis of variance between clusters was applied, and Euclidean Distance was selected as measurement.

\section{Result and discussion}

\section{Optimization of derivatization conditions}

The derivatization conditions including derivatization temperature $\left(50,70,90^{\circ} \mathrm{C}\right)$ and the reaction time $(30$, $60,90 \mathrm{~min}$ ) for the investigated compounds were optimized. On the other hand, the sufficient amount of derivatization agent is necessary for good derivatization efficiency. The amount of BSTFA (50, 100 and $200 \mu \mathrm{L}$ ) were also investigated using univariate approach. Peak area of each investigated compound in Ganoderma extract was used as the marker for evaluation of the 
derivatization efficiency. Finally, the optimum derivatization conditions, which had highest efficiency in short reaction time under mild temperature, were as follows: $100 \mu \mathrm{L}$ BSTFA reacted with free sterol and fatty acids in $400 \mu \mathrm{L}$ of n-hexane at $70^{\circ} \mathrm{C}$ for $30 \mathrm{~min}$.

\section{Validation of method}

SIM method of GC-MS analysis for simultaneous investigation of the analytes was used for the quantification and the fragment ions for simultaneous monitoring of analytes were listed in Table 2.

All the calibration curves showed good linearity within test ranges. The overall LODs and LOQs were less than $0.485 \mathrm{ng}$ and $0.971 \mathrm{ng}$, respectively (Table 2). The optimized method showed good precision for the quantification of 11 investigated components with intra- and inter-day variations less than $2.7 \%$ and $4.3 \%$, and the repeatability of derivatization detected in PLE extract of test sample (GL-1) was less than $3.2 \%$. The developed method also had good accuracy with overall recovery of $96.9 \%-101.9 \%$ for the analytes (Table 2). The results showed that the developed GC-MS method was sensitive, precise and accurate for quantitative determination of 11 investigated components in Ganoderma.

\section{Quantification of the investigated compounds in Ganoderma by GC-MS}

Typical TIC and SIM chromatograms of TMS derivatives of mixture of 11 reference compounds and PLE extracts of two species of Ganoderma were shown in Figure 2. The identification of investigated compounds was carried out by comparison of their retention time and mass spectra with those obtained by injecting standards in the same conditions. By using the calibration curves of each analyte, the contents $\left(\mu \mathrm{g} \cdot \mathrm{g}^{-1}\right)$ of ten fatty acids and one sterol in Ganoderma were determined, which were summarized in Table 3. The data showed that ergosterol, a characteristic compound in fungi, was abundant in both G. lucidum and G. sinense. PA, LOA, OA and SA were the main fatty acids in Ganoderma, which were in accordance to the results in G. lucidum spore [15].

\section{Comparison of free sterol and fatty acids in two species of Ganoderma}

In China, G. lucidum and G. sinense is recorded as Lingzhi in Chinese Pharmacopoeia. Ergosterol, as a specific component of fungal cell membrane, was also rich in G. lucidum and G. sinense. But the content of ergosterol in G. lucidum (median content $705.0 \mu \mathrm{g} \cdot \mathrm{g}^{-1}$, range 189.1-1453.3 $\mu \mathrm{g} \cdot \mathrm{g}^{-1}, \mathrm{n}=19$ ) was much higher than that in G. sinense (median content $80.1 \mu \mathrm{g} \cdot \mathrm{g}^{-1}$, range 16.0$409.8 \mu \mathrm{g} \cdot \mathrm{g}^{-1}, \mathrm{n}=13$ ), which is similar to triterpenoids and polysaccharides $[1,11,34]$. However, it was much lower than that reported before [11,35], which might attribute to the different sample and/or peak overlapping during HPLC analysis. Hierarchical clustering analysis based on the contents of ergosterol also showed that 32 tested samples of Ganoderma were grouped into two main clusters, G. lucidum and G. sinense, except two G. lucidum samples (Figure 3).

On the other hand, hierarchical clustering analysis based on the contents of ten fatty acids was also performed. The results showed that two species of Ganoderma had no significant difference though two groups were also obtained (Figure 3). Actually, the total content

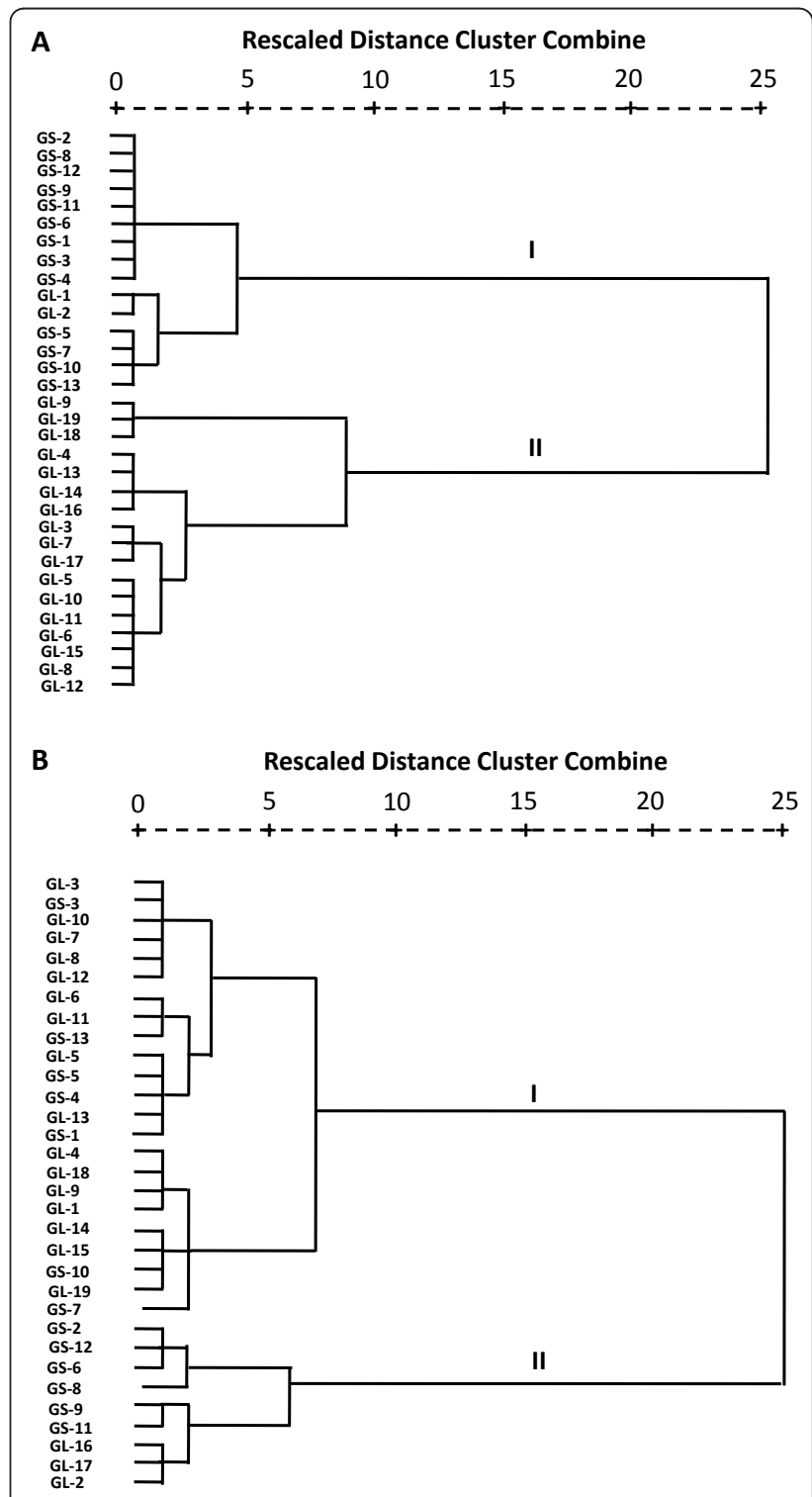

Figure 3 Dendrograms of hierarchical cluster analysis resulting from (A) ergosterol and (B) ten fatty acids in 32 tested Ganoderma samples. GL1-GL19 and GS1-GS13 were same as in Table 1. 
of fatty acids was higher in cluster II. Palmitic acid, linoleic acid, oleic acid and stearic acid were the main fatty acids in Ganoderma, which were in accordance with the previous reports for G. lucidum spore [15,36]. It was reported that fatty acids from the spores of G. lucidum could inhibit tumor cell proliferation. Nonadecanoic acid (C19:0) showed the highest inhibitory activity, followed by heptadecanoic acid (C17:0), stearic acid (C18:0, SA) and palmitic acid (C16:0, PA) [20]. Actually, saturated fatty acids including SA and PA are proapoptotic agents [37]. Unsaturated fatty acids LoA and OA have been revealed their anticancer activities [38-42] by activating GPR40 [38] and inducing oxidant stress and mitochondrial dysfunction [42] in cancer cell lines. Therefore, the similarity of two species of Ganoderma in fatty acids may be related to their antitumoral proliferation effect.

\section{Conclusion}

The content of ergosterol is much higher in G. lucidum than in G. sinense. Palmitic acid, linoleic acid, oleic acid, stearic acid are main fatty acids in Ganoderma and their content had no significant difference between G. lucidum and G. sinense, which may contribute to their antitumoral proliferation effect.

\footnotetext{
Abbreviations

DA: docosanoic acid; ErS: ergosterol; GC-MS: gas chromatography-mass spectrometry; LA: lauric acid; LoA: linoleic acid; LiA: lignoceric acid; MA: myristic acid; OA: oleic acid; PLE: pressurized liquid extraction; PtA: pentadecanoic acid; PoA: palmitoleic acid; PA: palmitic acid; SA: stearic acid; SIM: Selected ion monitoring; TIC: Total ion chromatogram; TMS: trimethylsilyl.
}

\section{Acknowledgements}

This study was partially supported by grants from the National Natural Science Foundation of China (No.30928033) and University of Macau (UL015A).

\section{Author details}

${ }^{1}$ State Key Laboratory of Quality Research in Chinese Medicine, University of Macau, Macao SAR 999078, China. ${ }^{2}$ Institute of Chinese Medical Sciences, University of Macau, Macao SAR 999078, China. ${ }^{3}$ Jiangsu Key Laboratory for TCM Formulae Research, Nanjing University of Chinese Medicine, Nanjing, Jiangsu, China.

\section{Authors' contributions}

SPL initiated and all authors designed the study. The extraction and method developments were conducted by GPL who drafted the manuscript. All authors contributed to data analyses and to finalizing the manuscript. All authors have read and approved the final version.

\section{Competing interests}

The authors declare that they have no competing interests.

Received: 5 December 2011 Accepted: 31 January 2012

Published: 31 January 2012

\section{References}

1. Liu YW, Gao JL, Guan J, Qian ZM, Feng K, Li SP: Evaluation of antiproliferative activities and action mechanisms of extracts from two species of ganoderma on tumor cell lines. J Agric Food Chem 2009, 57:3087-3093.

2. Chinese Pharmacopoeia Commission: Pharmacopoeia of the People's Republic of China 2010 Chemical Industry Press: Beijing; 2010.

3. Paterson RRM: Ganoderma - A therapeutic fungal biofactory. Phytochemistry 2006, 67:1985-2001.

4. Zhao S, Ye G, Fu G, Cheng JX, Yang BB, Peng C: Ganoderma lucidum exerts anti-tumor effects on ovarian cancer cells and enhances their sensitivity to cisplatin. Int J Oncol 2011, 38:1319-1327.

5. Xu Z, Chen X, Zhong Z, Chen L, Wang Y: Ganoderma lucidum polysaccharides: Immunomodulation and potential anti-tumor activities. Am J Chin Med 2011, 39:15-27.

6. Seo HW, Hung TM, Na M, Jung HJ, Kim JC, Choi JS, Kim JH, Lee HK, Lee I, Bae K, Hattori M, Min BS: Steroids and triterpenes from the fruit bodies of Ganoderma lucidum and their anti-complement activity. Arch Pharmacal Res 2009, 32:1573-1579.

7. Dudhgaonkar S, Thyagarajan A, Sliva D: Suppression of the inflammatory response by triterpenes isolated from the mushroom Ganoderma lucidum. Int Immunopharmacol 2009, 9:1272-1280.

8. Sato $N$, Zhang Q, Ma CM, Hattori M: Anti-human immunodeficiency virus1 protease activity of new lanostane-type triterpenoids from Ganoderma sinense. Chem Pharm Bull 2009, 57:1076-1080.

9. Weng Y, Xiang L, Matsuura A, Zhang Y, Huang Q, Qi J: Ganodermasides A and $B$, two novel anti-aging ergosterols from spores of a medicinal mushroom Ganoderma lucidum on yeast via UTH1 gene. Bioorg Med Chem 2010, 18:999-1002.

10. Seto SW, Lam TY, Tam HL, Au ALS, Chan SW, Wu JH, Yu PHF, Leung GPH, Ngai SM, Yeung JHK, Leung PS, Lee SMY, Kwan YW: Novel hypoglycemic effects of Ganoderma lucidum water-extract in obese/diabetic (+db/ $+\mathrm{db}$ ) mice. Phytomedicine 2009, 16:426-436.

11. Zhao J, Zhang XQ, Li SP, Yang FQ, Wang YT, Ye WC: Quality evaluation of Ganoderma through simultaneous determination of nine triterpenes and sterols using pressurized liquid extraction and high performance liquid chromatography. J Sep Sci 2006, 29:2609-2615.

12. Wang XM, Yang M, Guan SH, Liu RX, Xia JM, Bi KS, Guo DA: Quantitative determination of six major triterpenoids in Ganoderma lucidum and related species by high performance liquid chromatography. J Pharm Biomed Anal 2006, 41:838-844.

13. Pedrini N, Crespo R, Juárez MP: Biochemistry of insect epicuticle degradation by entomopathogenic fungi. Comp Biochem Physiol C Toxicol Pharmacol 2007, 146:124-137.

14. Roberts CW, McLeod R, Rice DW, Ginger M, Chance ML, Goad L: Fatty acid and sterol metabolism: potential antimicrobial targets in apicomplexan and trypanosomatid parasitic protozoa. Mol Biochem Parasitol 2003, 126:129-142.

15. Liu X, Xu SP, Wang JH, Yuan JP, Guo LX, Li X, Huang XN: Characterization of ganoderma spore lipid by stable carbon isotope analysis: Implications for authentication. Anal Bioanal Chem 2007, 388:723-731.

16. Shen M, Xie M, Nie S, Wan Y, Xie J: Discrimination of different Ganoderma species and their region based on GC-MS profiles of sterols and pattern recognition techniques. Anal Lett 2011, 44:863-873.

17. Smania EFA, Delle Monache F, Smania A Jr, Yunes RA, Cuneo RS: Antifungal activity of sterols and triterpenes isolated from Ganoderma annulare. Fitoterapia 2003, 74:375-377.

18. Zhao HB, Wang SZ, He QH, Yuan L, Chen AF, Lin ZB: Ganoderma total sterol (GS) and GS1 protect rat cerebral cortical neurons from hypoxia/ reoxygenation injury. Life Sci 2005, 76:1027-1037.

19. Hirasawa A, Hara T, Katsuma S, Adachi T, Tsujimoto G: Free fatty acid receptors and drug discovery. Biol Pharm Bull 2008, 31:1847-1851.

20. Fukuzawa M, Yamaguchi R, Hide I, Chen Z, Hirai Y, Sugimoto A, Yasuhara T, Nakata Y: Possible involvement of long chain fatty acids in the spores of Ganoderma lucidum (Reishi Houshi) to its anti-tumor activity. Biol Pharm Bull 2008, 31:1933-1937.

21. Huang SM, Yang XL, Zhu HS: Antitumor effects of triterpene acids extracted from Ganoderma lucidum. Envir Trans Engin 2011, 11:7398-7401.

22. Cai $Y$, Cai $T G$, Shi $Y$, Cheng $X L$, Ma LY, Ma SC, Lin RC, Feng $W$ : Simultaneous determination of eight PDE5-IS potentially adulterated in herbal dietary supplements with TLC and HPLC-PDA-MS methods. J Liq Chromatogr Related Technol 2010, 33:1287-1306.

23. Hsu SC, Ou CC, Li JW, Chuang TC, Kuo HP, Liu JY, Chen CS, Lin SC, Su CH, Kao MC: Ganoderma tsugae extracts inhibit colorectal cancer cell growth via G2/M cell cycle arrest. J Ethnopharmacol 2008, 120:394-401. 
24. Chen TQ, Zhao XY, Wu JZ, Yu DY, Wu YB: Supercritical fluid CO2 extraction, simultaneous determination of components in ultra-fine powder of Ganoderma sinense by HPLC-ESI-MS method. J Taiwan Inst Chem Eng 2011, 42:428-434.

25. Guan J, Li SP: Discrimination of polysaccharides from traditional Chinese medicines using saccharide mapping-Enzymatic digestion followed by chromatographic analysis. J Pharm Biomed Anal 2010, 51:590-598.

26. Huang SQ, Wei G, Yao SJ, Liu CL, Ning ZX: Optimization and comparison of fingerprints of triterpenoids from Ganoderma lucidum and Ganoderma sinense. J South China Univ Tec 2010, 38:121-125.

27. Keypour S, Rafati H, Riahi H, Mirzajani F, Moradali MF: Qualitative analysis of ganoderic acids in Ganoderma lucidum from Iran and China by RPHPLC and electrospray ionisation-mass spectrometry (ESI-MS). Food Chem 2010, 119:1704-1708.

28. Yang Q, Wang S, Xie Y, Sun J, Wang J: HPLC analysis of Ganoderma lucidum polysaccharides and its effect on antioxidant enzymes activity and Bax, Bcl-2 expression. Int J Biol Macromol 2010, 46:167-172.

29. Chen Y, Xie MY, Wang YX, Nie SP, Li C: Analysis of the monosaccharide composition of purified polysaccharides in Ganoderma atrum by capillary gas chromatography. Phytochemical Anal 2009, 20:503-510.

30. Huang SQ, Li JW, Li YQ, Wang Z: Purification and structural characterization of a new water-soluble neutral polysaccharide GLP-F1-1 from Ganoderma lucidum. Int J Biol Macromol 2011, 48:165-169.

31. Ye L, Zheng X, Zhang J, Yang Y, Meng Y, Li J, Chen W, Li A, Pan YJ: Composition analysis and immunomodulatory capacity of peptidoglycan from ling zhi or reishi medicinal mushroom, ganoderma lucidum (W. Curt.: Fr.) P. Karst. Strain 119 (Aphyllophoromycetideae). Inter J Med Mushrooms 2010, 12:157-165.

32. Cheung $\mathrm{HY}, \mathrm{Ng} \mathrm{CW}$, Hood DJ: Identification and quantification of base and nucleoside markers in extracts of Ganoderma lucidum, Ganoderma japonicum and Ganoderma capsules by micellar electrokinetic chromatography. J Chromatogr A 2001, 911:119-26.

33. Pedneault $K$, Angers $P$, Gosselin A, Tweddell RJ: Fatty acid profiles of polar and neutral lipids of ten species of higher basidiomycetes indigenous to eastern Canada. Mycol Res 2008, 112:1428-1434.

34. Ding P, Cai H, Liu Y, Lin L, Xu H: Comparison of the Components of Ganoderma lueidum and Ganoderma japonicum. J Chin Med Mater 1999, 22:433-434.

35. Liu JJ, Huang WH, Lv ML, Si JP, Guo BL, Li SJ: Determination of Ergosterol in Ganoderma lucidum from Different Varieties and Cultured Tree Species by HPLC. J Chin Med Mater 2011, 34:187-190.

36. Wang YJ, Zhang L, Ding AW: Quantification of five kinds of organic acids in Ganoderma Lucidum Spores Oil by GC-MS. J Nanjing Univ Trad Chin Med 2009, 25:136-139.

37. Hardy S, El-Assaad W, Przybytkowski E, Joly E, Prentki M, Langelier $Y$ : Saturated fatty acid-induced apoptosis in MDA-MB-231 breast cancer cells. A role for cardiolipin. J Biol Chem 2003, 278:31861-31870.

38. Yonezawa $\mathrm{T}$, Katoh $\mathrm{K}$, Obara $\mathrm{Y}$ : Existence of GPR40 functioning in a human breast cancer cell line, MCF-7. Biochem Biophys Res Commun 2004, 314:805-809.

39. Hasanzadeh GK, Latiffah AL, Hanachi P, Hj Lajis N: Effect of Linoleic acid of Nigella sativa on MDA-MB-231 human breast cancer cells. Iran J Cancer Prev 2011, 4:65-70.

40. Ohmori H, Sasahira T, Fujii K, Yi L, Shimomoto T, Kuniyasu H: Linoleic-acidinduced growth suppression induces quiescent cancer cell nests in nude mice. Pathobiology 2008, 75:226-232.

41. Carrillo C, Cavia MD, Alonso-Torre SR: Oleic acid inhibits store-operated calcium entry in human colorectal adenocarcinoma cells. Eur J Nutr 2011

42. Lu X, Yu H, Ma Q, Shen S, Das UN: Linoleic acid suppresses colorectal cancer cell growth by inducing oxidant stress and mitochondrial dysfunction. Lipids Health Dis 2010, 9:106-116.

doi:10.1186/1752-153X-6-10

Cite this article as: Lv et al:: Comparison of sterols and fatty acids in two species of Ganoderma. Chemistry Central Journal 2012 6:10.

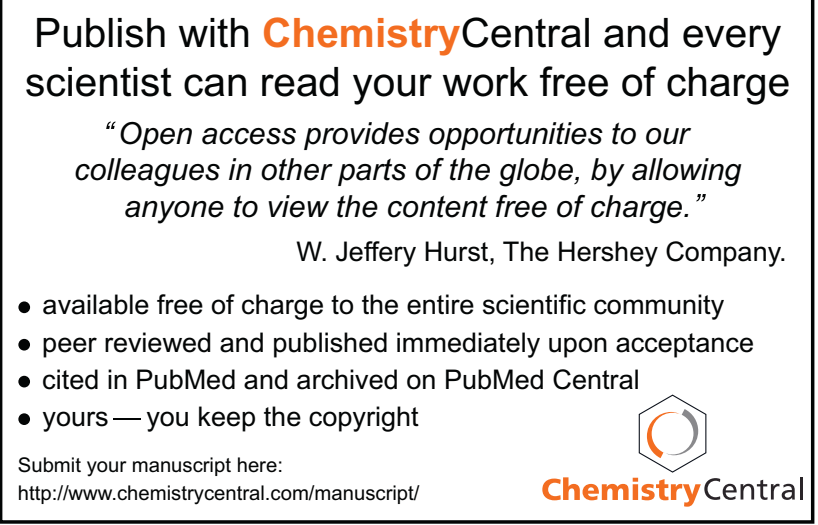

